\title{
Ontology of the Multitude and Heterarchy of the Common
}

\author{
Tapdyg Kh. Kerimov and Igor V. Krasavin* \\ Ural Federal University named after the first \\ President of Russia B.N. Yeltsin \\ Ekaterinburg, Russian Federation
}

Received 11.04.2019, received in revised form 06.07.2020, accepted 11.08.2020

\begin{abstract}
This paper explores ontology of multitude, reflecting the General Intellect theory by A. Negri, M. Lazzarato, P. Virno, M. Pasquinelli and others. General Intellect is used as a synonym of the cognitive capacity of society, that may either liberate it from capitalism or be exploited by the capitalistic organisation of society. In this paper, General Intellect is analysed as a property of a social connection structure, hereinafter referred to as heterarchy. The connection structure heterarchy forms different kinds of singularities, i.e. aggregations consisting of statistical repetitions of relations and individual egos creating values through their goal-setting and other intellectual activities. The article argues that though General Intellect may denote capacity for the self-organization of society to a certain extent, it is difficult to identify with the only particular institutional organisation or political regime. General Intellect manifests itself in any type of social structuring through self-organising processes.
\end{abstract}

Keywords: general intellect, heterarchy, singularity, complexity, aggregate, multitude, ego.

Research area: philosophy.

Citation: Kerimov, T.Kh., Krasavin, I.V. (2020). Ontology of the multitude and heterarchy of the common. Soc. Sci., 13(8), 1298-1309. DOI: 10.17516/1997-1370-0644.

\footnotetext{
(C) Siberian Federal University. All rights reserved

* Corresponding author E-mail address: krasavin.i@gmail.com, kerimovt@mail.ru ORCID: 0000-0002-2286-8412 (Kerimov); 0000-0003-0733-9114 (Krasavin)
} 


\section{Introduction}

This paper is based on the methodology of heterology, inherent to contemporary continental philosophy and social sciences. The reference to heterology entails a radical transformation of social ontology. This transformation is twofold: firstly, ontology transforms into ontogenesis, studying the becoming of various systems and phenomena; secondly, ontology transforms into heterogenesis, studying the becoming as the development of difference, plurality and multiplicity (Kerimov, 2012: 83). In a heterological sense, becoming always implies the development of difference and multiplicity. The problem that arises is how multiplicity, being heterogeneous, nevertheless organises and reproduces itself in the variable social order.

The convergence of social relations and its machinic organisation, developing by the post-operaist movement within the theory of General Intellect have become a central point of many recent discussions. The notion was prompted by K. Marx as he observed machine-aided labour organisation: labour organisation properties represent, in fact, a kind of a social "machine". According to A. Negri, "The general intellect is a machinic productive force, constituted by the multitude of corporeal singularities that form the topos of the common event of the general intellect. With the generation of the general intellect, we enter the epoch of the man-machine" (Negri, 2003: 205-206). Since communication has a multiple nature, the creative productivity of the General Intellect is expected to overcome the limitations imposed by the capital and grant the society a political and economic freedom (Lazzarato, Negri, 1991; Virno, 2004). It is important to clarify that General Intellect is also a virtual body or a machine, topologically composed by social connections produced "by the multitude of corporeal singularities". With this virtual body being a "social brain" (Wolfe, 2010: 366-374), it is not only its implicit creative capacity we are interested in but the particular form of the structure it is organized through.

As the initial metaphor for General Intellect was based on a comparison of machinic organisation of labour to the knowledge of a human mind materially produced by brain, we may extend it and use the notion of heterarchy originated in the early artificial neural network theories to define both the connection structure and the value formation principles. Despite its heuristic value, the concept of heterarchy is not clearly defined and is not frequently used. The main commentary was provided by W.S. McCulloch (McCulloch, 1945: 89-93), the author of the first theoretical artificial neural network model, in his brain neurones research. McCulloch associated the heterarchy of values with the concept of the whole, different parts of which tie together every single whole and contribute to its changes.

Concerning our research, heterarchy is a multitude of hierarchies connected by networks, thus composing aggregations of actors and relations. This structure is heterogeneous, which means that actors and relations are exterior to each other. For such a property of heterarchical relations, we use the term of exteriority as applied by M. Delanda to the analysis of multiplicity and social complexity (Delanda, 2006: 8). According to Delanda, exterior relations form the objects through assemblage, i.e. a process of cross-connecting relations, and heterarchy is a form of structure emerging through such a cross-connection.

We argue that being a structure of General Intellect, heterarchy may clarify its composition and properties as general for the society and its capacity to be intellect. Without this, General Intellect remains nothing but a beautiful metaphor. Further, with the help of the heterarchy concept, we will show that though General Intellect may denote capacity for self-organisation of society as an aggregate, it is difficult to identify with the only particular institutional organisation or political regime. General Intellect appears in any type of social structuring through self-organising processes.

\section{Ontology of Multitude: \\ Connection Structure as a Process}

First of all, we need to analyse ontology of multitude as a domain of social cognition and organisation to find how multiple relations may ontologically form social orders. Negri writes: "In contrast with the concept of the people, the concept of multitude is a singular multiplicity, 
a concrete universal. The people constitute a social body; the multitude does not, because the multitude is the flesh of life. ...the multitude is an active social agent, a multiplicity that acts. Unlike the people, the multitude is not a unity, but as opposed to the masses and the plebs, we can see it as something organised. In fact, it is an active agent of self-organisation" (Negri, 2002: 36). This kind of organisation has no centre, no exact border (an ontological "apartheid" between more and less real entities) or aim. Here Negri advocates Deleuzian understanding of multiplicity.

There are two fundamental aspects of multiplicity that should be highlighted here: firstly, its elements are virtual, and secondly, their mutual differential relations, corresponding to singularities, determine this virtuality, or potentiality. There is an opportunity for the differential ontology of multiplicities, one dealing with the virtual transforming into the actual. This ontology is incompatible with the concepts of the One and the Many: a multiplicity, in contrast to plurality, excludes any unitary instance. Ontologically, as pointed out by Deleuze and Guattari, parts and whole are the same, since parts may form many different wholes of the same relations (Deleuze, Guattari, 2000: 42-50). Since every movement causes a transformation of the whole, the whole as such should always be open. In other words, it is impossible to identify the whole with a kind of integrity or closeness of the system. If the whole is not the one, the reason is its being open and continually changing or contributing to the emergence of something new; in a word, becoming.

Here we are dealing with a dynamic structure which is always in the process of becoming. This structure is relational, as multitude is singular, related to the one and the many. However, how may social order(s) emerge? Negri states: "...Multitude is an ensemble of singularities whose life-tool is the brain and whose productive force consists in co-operation. In other words, if the singularities that constitute the multitude are plural, the manner in which they enter into relations is co-operative. How can the plurality and the co-operation of singularities express governance of the common, in so far as they form the constitutive power of the world? Within the teleology of the common... ontological transformation frees us from sovereignty" (Negri, 2003: 225-226).

Whereas the relations between the one and the many are determined by being (static ontology of unity), the relations between common and singularity are determined by becoming, that is, an ontology of multitude. The co-operation of singularities within the common produces new relations (or singularities) which, in turn, feed back into the (newly constituted) common engaging itself into co-operation with (newly modified) singularities, and so on. It is in this sense that co-operation of singularities in the common is produced and producing. Dynamic social structure is driven by the "teleology of common" where the common is a name for cooperation. It is here the first controversy arises. Negri writes that the common (which is a "living labour") is singular, differently affecting each member of the multitude (Negri, 2003: 182). Ironically, this means that the common, as well as the cooperation, does not belong to the multitude, so the common is simply not common, but the exterior, i.e., not only shared but also divided. The commonality of the common is formal, providing different actors with different fruits of labour. Therefore, it is difficult for the common to unify a plurality by imposing a teleology of common cooperation. If we wish to have a dynamic, singular structure of relations, which is in continuous motion of self-organisation without a command centre, we would suggest that the order (as the constitution of the whole) is recursive and comes from the exterior. Literally, this means that order comes from other people as individuals and groups (singularities), being plural and impossible to be completely subjugated to any kind of goal, including the goal of common cooperation. The latter is a multiple process organised from all aspects of the issue, which makes teleology impossible.

Heterarchy may provide an interpretation of structure as a multiple order designed from the exterior, without unifying the common as transcendent grounding or transcendental pre-supposition of the structure. Heterarchy holds the whole and its parts as immanent mul- 
tiple entities with different meanings depending on the environment and recursively combining different wholes co-existing together. No parts are exclusively predisposed to constituting a whole, and no whole is a transcendent grounding, exclusive goal or meaning for any organised parts, because each of them emerges simultaneously. Otherness, or exteriority, is extremely important here, as it would be not enough to say that heterarchy is just a multiple structure. For such a case, it could be a polyarchy or a network, and would not need inventing a new concept.

Heterarchy reflects the fact that relations and their meanings are not only multiple; they are also singular, i.e. have endless ways of embodiment. This means that the same relation for a particular group or an individual may contain many different meanings, and link these people to another group, organising an automatic causation process. Statistical multitudes emerge in a relational activity of some individuals. And as they emerge, not guided, the structuration process begins from the outside for any part and the whole of relations, evoking diverse meanings and agencies tied without the "common" intention. The forbiddance of transitivity proposed by McCulloch is the condition that explains how the exterior whole and parts may avoid a vicious circle of the teleology of common cooperation. It means that no particular relation or meaning can be taken as universal. Any composition of relations appears local, and a multiplicity of relations is topological. The more valuable are the relations, the more frequent and dense connections between them are made, the faster is the social time, the more complex is the social space and vice versa.

This is not surprising if we remember that neuron connections in the brain are structured in the same manner, i.e. the more frequent is the act (and the corresponding signals), the more dense neuron connections are formed. Negri reminds that "If we wish to give to the common name the direction of the arrow of time and place it in relation to its irreversibility without losing its singularity, it is necessary then that the common name is grasped as an act or praxis of temporality" (Negri, 2003: 160). Therefore, heterarchical relations take place in real time and imply process as their constitutive aspect. This proposition leads us to a paradox of a structure that appears as a process. Though the notion of structure is usually associated with stability and rigidity of order, here we have an order emerging through overlapping relations and different sequences of relations that give rise to different orders structured by the same heterarchical principle. In turn, if forbiddance of transitivity leads to the emergence of a processual structure, this structure is nothing but an embodied experience, or history of an object's becoming and its path dependency. This statement may be further articulated as an experience of irreversible time is the absolute requirement for the structuration of relations in a multiple environment.

How is it possible for the parts to be equally significant to the whole and for the order to come from the process but not an initial intention or idea? A solution was suggested by G. Tarde who described a model of multiple social relations without an initial intention, i.e. without a rational goal imposed on individuals or groups. Tarde called this process an imitation, which produces subjectivities through similarity and difference of partial and common attributes: individuals reflect features of their groups, just as groups are organised as compositions of the individuals' attributes, and not as subjects representing a social whole (Tarde, 1903: 37-43). Abstractly, these singular objects, organised by relations without intentions, may be referred to as fractals. Omitting the mathematical definition of fractals, it can be said that social fractality is an undeniable full or partial similitude of relations. Fractality reflects the above-mentioned properties of recursiveness of the whole and its parts, with the meaning of relation dependant on the interaction and creation of different orders and structures through a process. Being fractals, they are constituted by the mimesis of the wholes and their parts through difference and repetition. In other words, the source of social diversity is at the same time the source of order. Social relations are not only singular; they are also typical and differ by various patterns of organisation, coordinated by the processes of relations themselves through association in 
irreversible time. The organisation of society implies reproduction and change of the assembling localities, and the virtual heterarchical structure is the order for the temporal sequence of topological allocation of social relations.

Since individuals and groups, as Negri asserts, become singularities i.e. relational objects, they cannot be completely identified with a particular attribute, rationality, profession, ethnicity, etc. Identifications become processual, and reproduction of new attributes means their recursiveness in the networks of singularities. Overlapping networks of relations produce recursive hierarchies that emerge on multiple associations of singularities. Multiplicity, therefore, is the origin of hierarchy as well of the network. Multiple networks accompany hierarchies and recursive hierarchies accompany networks. Aggregations of singularities reproduce themselves through simulation of unity in a fractal way as a similitude of the diverse. Such a quality acquired by singularities may be usually observed in small groups where a group submits its members. As Delanda shows in his social complexity theory, at the macro scale we may see the properties of the unique individuals, taken in statistical aggregations and spread in time and space, appear as the collective ones, aimed toward the goals that individuals are not aware of. Yet, being statistical sets, general singularities continue to be individual ones with their own path in time and a place in space of relations (Delanda, 2006: 16-18). Whether it is a group, a community, or a nation, any collectivities that detect their identifications post-factum, are examples of this process.

Therefore, we may say that the establishment of any singular network is pre-supposed by a hierarchy of aggregation as a whole and vice versa, a hierarchy is pre-supposed by networks. Relations remain multiple in networks but localized by matching hierarchies. Any hierarchy is aggregated by overlapping neighbouring networks of singularities and its description will therefore always imply connections and meanings of contiguous entities. It is a singular actor of networks and an element of hierarchies, thus combining the macro and micro scales of relations. Singularities actualize interactions to the extent to which they are elements of a more general hierarchy and a relevant order other than themselves. Relations of singularities are not based on the only hierarchy or network; they involve relationships with other hierarchies of more general and local orders, as well as relationships with contiguous networks. As a result, elements of two different hierarchies can interact only within the boundaries of a third, partially common or differentiated hierarchy. A network from one hierarchy cannot be moved into the space of another or establish an equal relationship with it. In a manner of speaking, hierarchies multiply in the process of network differentiation. That is why social relations tend to be conservative, whilst the elements of one hierarchy remain passive in their relations with elements from other hierarchies.

Nevertheless, networks of singularities, but not hierarchies of identities, prove to be a tool for the multiplication of ordered systems. By singular nature of the social, activity spreads through mobile networks, making it impossible for a heterarchy (as a social connection structure) to subjugate to a particular institutional order (Krasavin, 2017: 138). All this considered, social relations are network-forming hierarchies, heterarchical organisation of which automatically emerge on the activity of singularities. Such relational assemblage is metastable, so the positions of singularities in a connection structure, the forms of their subjectivity and the forms of their activity are mutually dependent. Their connections line up through the topological distribution and the temporal irreversibility of ties. Time is irreversible, but relations are reversible. Types of relations are finite, but the variety of situations is infinite.

\section{Transformations}

\section{of Multitude and General Intellect}

The connection structure proposed above should help us to clarify whether metaphysics of the 'common' of multitude described in (post)operaismo may form General Intellect acting as a means of liberation from the shackles of capitalism. For this purpose, we have to analyse the social order-determining capacity of the organisation of multitude and Gener- 
al Intellect, keeping in mind the properties of heterarchy described above. The multitude is the main concept of General Intellect theory as the only visible, material part of general cognition. Borrowed by A. Negri from A. Matheron, it means a decentralized organisation of relations, representing the process of association that forms social groups from the sets of individuals (Matheron, 1988; Negri, 1991: 109, 140.). The multitude members become singularities, structurally located between the particular individuals and the general collectivity of society.

Since being promoted by Negri, the notion of the multitude has faced various criticisms. P. Macherey and E. Laclau found that the heterogeneous nature of multitude was the main obstacle for its political use. In their opinion, interpreting multitude as a political body implies subjectivity as a general volition towards a certain goal, which turns society into a single entity. Acting as a political body and making decisions requires unity and a guiding hegemonic force to emerge on the initial social multiplicity. This means a miraculous transformation of singularities at the moment when a political decision is made by some political activists united at least by common values of revolution or something else (Laclau, 2005: 153). Being united, as E. Balibar suggests, the multitude becomes ambivalent, since silent obedience is at least as frequent as a spontaneous rebellion. As multitude lacks 'internal political criteria', it may equally guide social solidarity both to peaceful and aggressive actions (Balibar, 1993: 3-38). Without any circumlocution, S. Zizek and $\mathrm{A}$. Badiou issued a verdict that multitude is a political force of domination mirroring decentered organisation of the capital (Badiou, 2003: 125; Zizek, 2006: 261-267). In other words, the multitude may easily appear to be the origin of the capital despotism, as well as a democracy may turn out to be an ochlocracy.

Responding to this criticism, Negri interprets the multitude differently, describing it is as a network of whatever actors, ties, values etc. In this case, the multitude becomes a kind of rhizome (Negri, 2002). Then, interpreting society as a multitude means that there are many different foundations and forms of sociality united only by the fact of their relation to some object. The meanings of these relations can be different for many actors, and it is enough to be considered a part of a social whole. Anyone is considered a part of the multitude and contributes to "the primary fount of the valorisation of the world' by intellectual activity. Singular multitude continually strives between the activities of individual singularities and the activities of bigger wholes, general singularities known as social groups and communities (consisting of persons and organisations). The flow of becoming singularities makes the multitude an irreversible continuum of relations. Irreversibility of multiple relations overcomes any institutional restriction. It equally establishes and destroys ties of individual and general singularities. For Negri, this is a hope for emancipation, but again, an ontological presence cannot be equally turned to the political order. In other words, irreversibility does not aim toward a particular singularity, capitalistic or communistic.

What unites multitude without unification is General Intellect; social communication that produces subjectivities and knowledge. The latter requires another mode of organisation and another type of actor rather than singularity or an aggregate. Another type of actor is an ego seeking goals and producing knowledge; another mode of organisation is a hierarchy. As pointed out above, a hierarchy emerges through the recursiveness of relations in overlapping networks of singularities. Each of the social conditions overlaps with others, turning the multitude of special features into a community of singularities. Besides, hierarchy does not only appear to be a means of exterior organisation; it is also a mode of interior reproduction of singularities. Due to the recursion of relations, they can be temporally and finitely manipulated for the sake of a common goal. Hierarchy reduces multiplicity to the simulation of unity through the coincidence of reasons and goals of relations and the point of coincidence is hierarchy itself. Therefore, through the delay and operation of time, it interiorises the relations and properties of singularities, and with the help of hierarchy, singularities mediate processes, assemble ties and synthesise values 
(senses), i.e. act as goal-seeking egos that are different to aggregations.

We may see that aggregate and ego supplement each other, while the latter represents the development of the former, though remaining exterior. This power of ego is more successful when supported by fluctuations of aggregates. Ego and any hierarchical institutions are limited by their finite goals and capacity of volition, which, at the macro scale, make them similar to aggregates, actuated by repeated relations. That is why an irreversible motion of aggregates can overcome the power of ego. The process, in which ego and aggregate correspond to each other, is a "living labour", or "the common", the multiple and singular that in any particular case overcome exploitation by a particular mode of relations (Negri, 2003: 225-235).

As a social cognitive capacity, General Intellect comes from the living labour, or the common, produced by the multitude in the form of information and knowledge. Here we see that analysis of social relations leaves the rigid institutional structures, certain modes of production and means of their evaluation behind. "Living" means variability of labour, absence of strict means for evaluation, i.e. ones to be reified in the model of discrete material objects or institutions. If information and knowledge cannot be ultimately located, they also cannot be manipulated through attribution to certain properties. They are displaced, remaining at the same place; the one who gives it does not lose it. These properties of information and knowledge have been known for a long time, but our task is to understand the relations that produce and organise information and knowledge as the common, into General Intellect as a whole.

Though the common cannot be reified, it can, nevertheless, be structured in some way. Information and knowledge differ from each other as they form different objects. As a collection of data, information is an aggregation or an aggregative state of knowledge. As such, information has only quantitative properties, but no qualitative ones. Information becomes knowledge when it is attributed to the ego, i.e. to the actor with certain goals and actions. Therefore, recognition of some data as infor- mation or as knowledge depends on the actor. It would not be exaggerated to say that knowledge defines one's capacity of having goals and consequences of actions, therefore subjectivizing an actor. Thus, being an aggregate of properties and qualities, the actor turns into an ego with its goal-setting. Of course, we may continue that every ego is a part of more general aggregates, and some of them (as groups, organisations) also possess some properties of ego.

Depending on the environment and configuration of ties, individual singularity transforms information to knowledge in different ways and uses it differently as well. Information also naturally circulates within particular communities. Through the organisational hierarchy, community acquires better cognitive capacities actualized in goal setting activities. This contributes to the concealment of information and the growth of knowledge. Acting as an ego, as a mediator, an institutionally reproducing community may exploit the "structural holes" (Burt, 1992, pp. 30-37) in the social whole to acquire benefits and power. In its turn, power, especially the power of capital, excels by governing social ties as aggregates. Here we face two sides of operation of aggregates; on the one hand, an opportunity for the ego to exploit them means that the inequality will be never overcome. On the other hand, the lack of total control of aggregates by the ego means the inevitable overcoming of any totalitarianism, which always remains temporary and partial. This means that "making a multitude" and exploitation of a multitude is a process that never comes to an end. General Intellect provides opportunities for both sides of the issue and may be used equally for liberation and hegemony.

\section{General Intellect, Heterarchy and New Forms of Organisation}

Let us now examine some opportunities and limits of exploiting General Intellect using the example of "living labour" management in IT companies and the possible threats to society. Corporative sociology (after followers of Gramsci) has already become aware of cognitive organisation and provided some reasoning on the subject. In his research, D. Stark writes 
about a new kind of managerial organisation in terms that are almost indistinguishable from the concept of General Intellect given by P. Virno (Virno, 2007). This new organisation represents an organisational form of a "distributed intelligence in which units are laterally accountable according to diverse principles of evaluation" (Stark, 2011: 19). According to Stark, this happens in the processes of brokerage and entrepreneurship among organisations when specific individual and hierarchized organisations mediate the work of other actors or include them in their system of relations. In other words, one hierarchical organisation, which has access to another, can contribute to the establishment of a certain joint structure of relations. For Stark, this structure presents an "organisation of dissonance" making social complexity work for different accounts of worth. For Virno (and Negri definitely would agree with this), the differently evaluated "distributed intelligence" is that very General Intellect he associated with emergent variable social structure. Surprisingly, the corporate management theory inspired by the example of Silicon (V)Alley with its typical style of communication between programmers, came to the same conclusions as the Italian Operaismo thinkers. What is more surprising, the name for the new kind of structure given by Stark was heterarchy.

Put into practice, this organisation method could solve the main problem of social theory, the issue of difference between structure and action, or, in the context of this paper, between action and cognition. Stark proposes to merge aggregative social complexity and goal-setting activity of ego in an organisational structure. However, this technique is just an exception to the rules; in social practice, heterarchy (and its promising economic prospects in the form of distributed intelligence) is hardly susceptible to formalization. The irreversibility of time and topological distribution of processes, leading to the complexity of relations, is the main impediment. Every hierarchic organisation is a kind of ego limited by its own goals. A liner merger usually interrupts their work. Of course, they can establish a kind of mediator, but that organisation, being an ego itself, will also be limited by its own finite goals. If it merges the previous two organisations and redistributes their tasks and results, we will see a hierarchy, not heterarchy. The presence of goals and values points at the finitude of organisation, subordinated to a hierarchical order, whereas a heterarchy, being multiple, overcomes particular order through establishing many different orders as aggregations of singularities. Different hierarchies belong to different situations (localities in the heterarchichal space of relations), while their connections establish the third situation, which is not associated with the targets of the first two and so on. This change is endless and heterogeneous.

In the case of relatively small organisations like start-ups and other forms of petty bourgeois business, diverse principles of evaluation are possible, but the multitude of petty bourgeoisie (usually called market) naturally produces large hierarchical organisations that sublate original heterogeneity (or operate it in the process of project management). Any organisation exists as overlapping communities, i.e. an aggregative multitude and as a recursive hierarchy with finite and perpetuate goals. These two contradict each other; indeed, they may exploit each other, but they cannot merge. Their general intellect does not automatically emerge; it sporadically appears in local situations.

It is important to remember the other side of General Intellect mentioned earlier in this article, which is the potential of exploitation and control over the society. As Verscellone and Pasquinelli already put it, the development of IT may increase the surveillance capacity of power and capital (Vercellone, 2007, Pasquinelli, 2013: 49-68). Any technological innovation that eases aggregation of relations in the form of data will sooner or later lead to the growth of control over the multitude. This will happen even if the initial idea of innovation was exactly the reverse. The Internet itself is one of the best examples of this case. Initiated as a libertarian community, now it provides opportunities for shadowing. The blockchain technology that traces all the motions of transactions on the Internet is even a better example. Using this innovation, people can control 
their money and properties and trust each other, which means that they do not need mediators for their financial operations anymore. Does it mean that banking will soon disappear and communistic libertarianism will emerge? There is a particular technology that makes all aspects of this issue possible. It will be used not only by private individuals and small enterprises; it will be used by big corporations to control all the transactions to combine their technical and financial power. Acting as egos, several supercompanies will compete with the multitude of other singularities, and the results of this competition cannot be predicted in advance. As power and capital are exteriorly organised hierarchies of networks, aggregation of these networks of singularities is used not only to overcome them but also to help them reproduce.

The last thesis about exteriority of power and capital, however, may clarify the limits to which exploitation of General Intellect extends. Exteriority of power means that it comes rather from an agreement of obedient bodies than from charisma or special intentions. Of course, surveillance gives lots of opportunities for control and manipulation of life, knowledge and human communication, but it does not mean that the forces of exploitation have a programme for our lives and communication. Such totalitarian projects have already happened in recent history and proven to be utopian. Capitalism is survivable precisely because of the absence of additional ideology except for the simple idea of "buy cheap to sell dear". It serves and exploits any kind of social organisation which accepts any privacy. If mere life and human communication become the origins of the accumulation of capital and the form of institutionalized power, so multiplicity and exteriority of their organisation putting a limit to the authoritarianism of power and egoism of capital. Total subordination of heterarchical structure of social ties is impossible, which also causes impossibility of subordination of the General Intellect that changes in the relations and choices of singularities. Like heterarchy, General Intellect is perceived as a virtual entity; can a virtual entity be exploited by the powers of domination or liberation? Like het- erarchy, General Intellect excels any hierarchic order with goals, let them be imposed by liberation or exploitation.

As a connection structure, heterarchy reveals properties that make opportunities for exploitation of General Intellect or using it for overcoming capitalism (or any other social order) very limited. General Intellect is seen as the development of relations established by ties of singularities and, therefore, combines the attributes of cogito and conatus. Total subjugation of General Intellect to whatever goals is impossible for, being an aggregate of a social whole, it retroactively affects all the singularities of the multitude. Due to irreversibility of time and topological configuration of ties, any particular singularity, an aggregate or ego with its political or economic goals will always be dependent on its location in the connection structure. Heterarchy and General Intellect provide opportunities for the emergence of aggregation and formation of egos, but no more. It does not serve for particular social order as it produces all the orders simultaneously.

As the brain does not suspect of the ego, the General Intellect made by social heterarchy is not aware of cognitive or any other capitalism. Due to the difference between aggregates and egos, General Intellect is not ego-centred, so it cannot be subjugated though it is partially possible to operate its self-organisation. Even if General Intellect is assimilated to the assemblage of information machines, as Pasquinelly put it, such an exegesis will be insufficient. Information machines are organised around certain functions and have no ego, i.e. do not appear as a species, that makes a decision (transforms information to knowledge) on its own in the process of irreversible time. If there is no common ego - there is no General Intellect seeking particular goals, there is only the General Intellect as self-organisation of aggregations of singularities.

\section{Conclusion}

The model of heterarchy provides opportunities and imposes limitations on social relations and therefore casts light on the extent to which the phenomenon of General Intellect can be embodied in the virtual structure of 
social connections and a specific institutional organisation. In this case, it is important to remember that the introduction of the notion of heterarchy by S. McCulloch was directly connected with his theoretical artificial neural network model in which the transitivity law is forbidden. The restriction imposed on the law of transitivity proves useful here since it prohibits the scaling of any property without alteration of objects or relations. That is, it refers to the capacity for thinking as well as connection to a social institution. Therefore, heterarchical structure inevitably implies complexity and increasing multiplicity in irreversible time, which the human mind and program code constantly face. If General Intellect is something more than a metaphor, then the restriction of transitivity and uncontrollable complexity should become its inherent properties.

A heterarchically-structured society is always a General Intellect since it organises itself in irreversible time through the association of heterogeneous relations. Machines and media accelerate communication, making it more visible and partially computable, but they do not replace or reproduce it, since they do not see it as the reason for existence as people do. Of course, the actions of people and organisations are limited by their goals and functions but unlike machines, they make decisions on their own.

The multiple structure of heterarchy provides society with the experience and automaticity of action but denies its reflection as a source of organisation. Some opportunities provided by the General Intellect can be used, but it cannot be forced to conform to a specific institutional order. Control and variation have the same source: hierarchies of relations proliferate in a heterarchy while networks are a tool of proliferation. Along with control and application methods, the General Intellect produces methods of liberation, which come laden with new limitations. By destroying industrial institutions, network organisation has brought new hierarchies of control. This process is irreversible and only partially controllable: the processes and composition of topological distribution can vary while self-organisation of multitude will always remain exterior to any social order.

\section{References}

Badiou, A. (2003). Beyond Formalization. In Angelaki, 8 (2), 111-136.

Balibar, E. (1994). Spinoza, the Anti-Orwell: the Fear of the Masses. In Masses. Classes. Ideas. New York: Routledge, 3-37.

Burt, R. (1992). Structural Holes. The Social Structure of Competition. Cambridge: Harvard University Press. 313 p.

Delanda, M. (2006). A New Philosophy of Society. Assemblage Theory and Social Complexity. London: Continuum. $150 \mathrm{p}$.

Deleuze, G., Guattari, F. (2000). Anti-Oedipus; Capitalism and Schizophrenia. London: Continuum. $712 \mathrm{p}$.

Kerimov, T.Kh. (2012). Philosophy Concepts in the Contemporary World. In Journal of Siberian Federal University. Humanities \& Social Sciences, 5(1), 76-85.

Krasavin, I. (2017). Heterarchy of the Multitude. In Logos, 3, 173-198.

Laclau, E. (2005). On Populist Reason. London: Verso. 288 p.

Lazzarato, M., Negri, A. (1991). Travail immateriel et subjectivite. In Futur Antérieur, 6, 86-89.

Matheron, A. (1988). Individu et Communaute chez Spinoza. Paris: Minuit. 647 p.

McCulloch, W.S. (1945). A Heterarchy of Values Determined by the Topology of Nervous Sets. In Bulletin of Mathematical Biophysics, 7, 89-93.

Negri, A. (1991). The Savage Anomaly: The Power of Spinoza's Metaphysics and Politics. Minneapolis: University of Minnesota Press. 277 p.

Negri, A. (2002). Approximations towards an ontological definition of the multitude. In Multitudes, 9, 36-48. 
Negri, A. (2003). Time for Revolution. New York: Continuum. 288 p.

Pasquinelli, M. (2013). Italian Operaismo and the Information Machine. In Theory, Culture \& Society, $0(0), 1-20$.

Pasquinelli, M. (2009). Google's PageRank Algorithm: A Diagram of the Cognitive Capitalism and the Rentier of the Common Intellect. In Deep Search: The Politics of Search Beyond Google. London: Transaction Publishers, 152-162.

Stark, D. (2011). The Sense of Dissonance: Accounts of Worth in Economic Life. Princeton: Princeton University Press. 264 p.

Tarde, G. (1903). The Laws of Imitation. New York: Henry Holt and Company. 450 p.

Vercellone, C. (2007). From Formal Subsumption to General Intellect: Elements for a Marxist Reading of the Thesis of Cognitive Capitalism. In Historical Materialism, 5 (1), 13-36.

Virno, P. (2004). A Grammar of the Multitude: For an Analysis of Contemporary Forms of Life. New York: Semiotext(e). $117 \mathrm{p}$.

Virno, P. (2007). General intellect. In Historical Materialism,15 (3), 3-8.

Wolfe, C. (2010). The Social Brain: a Spinozist Reconstruction. In Proceedings of the 9th Conference of the Australasian Society for Cognitive Science. Sydney: Macquarie Centre for Cognitive Science, 366-374.

Zizek, S. (2006). The Parallax View. Cambridge, Mass.: MIT Press. 429 p. 


\title{
Онтология множества и гетерархия общего
}

\author{
Т.Х. Керимов, И.В. Красавин \\ Уральский федеральный университет им. первого \\ Президента России Б.Н. Ельциина \\ Российская Федерачия, Екатеринбург
}

\begin{abstract}
Аннотация. В статье исследуется роль онтологии множества в обосновании гетерархической структуры общего. Это обоснование конкретизируется в определении ряда понятий и методологических средств теории общего интеллекта, которая развивается в интеллектуальном движении (пост)операизма. В данной теории общий интеллект используется для обозначения когнитивной способности общества, которая может освободить человека или быть эксплуатируема капитализмом. Общий интеллект является способностью общества к анализу, постановке целей, производства и одновременно виртуальным телом, топологически составленным социальными связями «телесных сингулярностей множества». В данной статье общий интеллект анализируется в качестве свойства структуры социальных связей (соединений), названной здесь гетерархией. Гетерархия в качестве структуры связей формирует различные виды сингулярностей: агрегаты (совокупности), производимые статистическими повторениями отношений, и индивидуальные эго, полагающие значения через постановку целей и другую интеллектуальную деятельность. Основной аргумент статьи заключается в том, что хотя в некоторой степени общий интеллект может обозначать способность к самоорганизации общества, его трудно отождествить только с одной конкретной институциональной организацией или политическим режимом. Общий интеллект появляется в любом виде социального структурирования посредством процессов самоорганизации.
\end{abstract}

Ключевые слова: общий интеллект, гетерархия, сингулярность, сложность, агрегат, множество, эго.

Научная специальность: 09.00.00 - философские науки. 